\title{
Anticipated and Unanticipated Transitions as Triggers for Adult Learning
}

\author{
Christin Tønseth \\ Department of Education and Lifelong Learning, Norwegian University of Science and Technology, Trondheim, Norway \\ Email: Christin.tosneth@ntnu.no
}

How to cite this paper: Tønseth, C. (2018). Anticipated and Unanticipated Transitions as Triggers for Adult Learning. Creative Education, 9, 165-181.

https://doi.org/10.4236/ce.2018.92013

Received: October 23, 2017

Accepted: February 8, 2018

Published: February 11, 2018

Copyright (C) 2018 by author and Scientific Research Publishing Inc. This work is licensed under the Creative Commons Attribution International License (CC BY 4.0).

http://creativecommons.org/licenses/by/4.0/

\begin{abstract}
Through life, most people experience challenges that affect both their private life and working life. The attention on transitions as promoters of adult learning has gained much attention in recent years, as the modern life with globalization and individualization has made life unpredictable, uncertain and risky. Based on interviews with 24 adult participants in different learning activities, the purpose of this study is to examine how adults emphasize transitions as triggers that lead to participation in learning. Findings presented in this paper indicate that transitions in adults' life are both associated with certain life-phases that support underlying age-based theories about adults' life structure, and transitions that adults are constantly faced with as a part of a continuous evaluation and reflection over life-possibilities and -utilization. Most interesting is the results indicating that various changes and transitions occur simultaneously and reinforce each other as triggers for adult learning.
\end{abstract}

\section{Keywords}

Adult learning, Transitions, Participation, Motivation, Triggers for Learning

\section{Introduction}

Life transitions have become a focus of attention among researchers in the field of adult education. In the modern society, people have learned to expect uncertainty, regardless of whether things are actually changing or not. And even when you do not really expect something to change, you are aware that other people's decisions might affect you at any time-in your job, in your family, in your home, or in your leisure activities. Transition is a fundamental feature of life in late modernity, and as adults we need to dip in and out of education and learning, constantly seeking insurance against the risks and uncertainties of tomorrow (Bauman, 2005). Based on interviews with 24 adult participants in different 
learning activities, the purpose of this study is to examine how adults emphasize different transitions as triggers that lead to participation in learning.

\section{Transitions in Adults' Lives}

Transitions are associated with periods of change in our lives that alternate with periods of stability (Aslanian \& Brickell, 1980; Merriam, 2005). We all go through numerous of transitions in our lives-leaving high school to go to college or work, changing jobs, getting married, having children, getting divorced and so forth. Major life transitions can be an exciting, challenging, and invigorating part of life. Such changes can also mean reorientation in life where learning becomes actualized.

Merriam (2005) argues that life changes can be predictable and linear as well as unpredictable and nonlinear. The modern society poses new challenges, but also greater maneuverability where people are relatively free in shaping their own life regardless of age, social class and economy (Gallacher, Ingram, \& Field, 2009: p. 3).

Some life events, such as marriage, graduation, or a career move, are mostly anticipated and planned for; others, such as illness, job loss or unexpected money coming in are unanticipated. All of these life events are "benchmarks in the human life cycle", that give "shape and direction to various aspects of a person's life" (Danish, Smyer, \& Nowak, 1980: p. 342).

Neugarten (1976: p. 16) argues that such life events may not be experienced as crises if they occur on time, as part of the expected life cycle. For example, as we get older, we recognize that death is coming closer, but when death happens to someone "young", shock and anger can be amplified. In Levinson's (1978: p. 49) definition, it is life events and the related social roles that they involve that create the "structure change", or transition periods, in our lives. Schlossberg, Waters and Goodman (1995) equate transitions with "life events entailing change" (p. 18). In a slightly expanded definition, they write that a transition is "any event, or nonevent, that results in changed relationships, routines, assumptions, and roles" (p. 27).

\section{Types of Transitions}

Transitions can be anticipated or unanticipated. In addition, nonevent transitions and "sleeper" transitions are mentioned (Schlossberg, 1989: p. 23). Anticipated transitions are life events that are expected to occur in most adults' lives, like getting married, finishing school, going to work and having children. Within particular cultural contexts, such events are predictable. The most obvious age-based transitions are the moves from kindergarten into school, from education into work, and from work into retirement. Such transition also involves generational roles, such as transition into marriage, into parenthood, and into grandparenthood. As Neugarten (1976: p. 16) pointed out, there is a "socially prescribed timetable for the ordering of major life events". Although there is 
variation in the actual experiencing of these life events and the norms may change over time, the overall "normative pattern is adhered to, more or less consistently, by most persons within a given social group" (p. 16). A longitudinal study of Canadian teenagers and their transition to young adulthood (Thiessen \& Looker, 1999), revealed strongly held norms about the key transitions of working a full-time job, marriage, having children, and school completion. Although there was consensus on the importance and preferred sequence of these transitions between the 1989 and 1994 surveys, there was quite a bit of variability in the actual experiencing of these transitions. This study illustrates both the normative expectations and individual variability with regard to anticipated life transitions.

Unanticipated transitions are the events that are unexpected and occur regardless of typical time in adult life. Winning a lottery, developing a health problem, getting laid off or fired from a job, losing a partner or family members, an accidents/illness, and being the victim of a crime are examples of this type of transition. These events are likely to be especially stressful; at the same time, their potential for stimulating learning and subsequent development may be greater than for the more normative, anticipated life events (Merriam, 2005: p. 5). Nonevent transitions "are the ones an individual had expected but which did not occur, thereby altering his or her life; the marriage that never occurred, the promotion that never materialized, the child who was never born, the cancer that did not metastasize" (Schlossberg, Waters, \& Goodman, 1995: p. 29).

Nonevent transitions are particularly intriguing, because although they too might stimulate adult learning, educators have failed to acknowledge them from a programmatic perspective. According to Schlossberg, Waters, and Goodman (1995: p. 30), these "hidden" motivators can take on several forms. Personal nonevents are the aspirations a person has about his or her life that do not materialize, like being promoted or getting married. Ripple nonevents are "unfulfilled expectations of someone close to us, which in turn, alters our own roles, relationships, and assumptions" (p. 30). For example, there can be a ripple effect when a spouse does not get an anticipated promotion. Resultant nonevents are the result of another event, such as the adult child who chooses not to have children, thus resulting in one's not becoming a grandparent. The fourth type of nonevent transition is the delayed nonevent. These are events that still might happen, like getting pregnant after giving up trying. Yet another type of transition might be called the sleeper transition (Schlossberg, 1989: p. 23). This is something that occurs gradually, and perhaps goes unnoticed for a while, but culminates in a change. The gradual deterioration of a relationship is a negative example; becoming increasingly competent, independent, or self-assured is a positive example. In any case, we eventually realize that "our roles, relationships, and routines have all been altered" (p. 23).

Both the Life History Project at Roskilde University (Salling Olesen, 2000) and The Learning Lives project (Biesta et al., 2011) emphasize the individual acquisi- 
tion of new life conditions in the modern society that generate new learning opportunities. The Learning Lives project combined longitudinal life-course and life-history data with data from large scale survey research. The main focus was on the inter-relationships between learning, identity and agency in the life course. The results showed that learning had to do with the ways in which individuals respond to events in their lives often in order to gain control over aspects in their lives. The events to which individuals respond to by participation in learning were either structured expected transitions or changes of a more incidental nature, including critical incidents such as redeployment or illness. Many such events resulted in forms of tacit learning that individuals sometimes became aware of after the event (Biesta et al., 2011).

In the late modernity's more complex social structure, change is embraced and perpetual renewal of motivation and striving is what modernization requires of most people most of the time, especially in their functional roles in the social systems (Field, 2013). From this standpoint, we can understand individuals in contemporary societies as "permanently learning subjects" who are inescapably the authors of transitions, for themselves as well as for others, and are also the objects of transitions.

A number of researchers have turned to theories of late- and post-modernity to account for these trends (Bauman, 2005; Edwards, 1997; Field, 2006). For instance, Giddens (1991) and Beck (1992), who are reflexive modernization theorists, suggest that individuals must continually cope with recurrent and complex transitions in life, where learning is actualized. In postmodern times, the search for identity represents the struggle to escape from uncertainty (Bauman, 2005). As a result of rapid technological, economic, cultural and social change, individuals are constantly faced with transitions in their personal and professional circumstances. Governments exhort their citizens to prepare for a life of permanent adaptation and flexibility (Field, 2011). Education and learning in adult life become both a resource for individuals seeking to promote transitions represented by employability and mobility, and at the same time represent a possible tool to cope with complex transitions, uncertainty and risk (Field, 2009: p. 4).

The process of individualization has been assumed to create greater freedom for individuals, who have increased opportunities to choose and to break free from ascribed roles in different contexts. These opportunities to shape one's life trajectory also make people more dependent on educational success (Brown, 2003). Pita Castro (2014: p. 122) names such types of transitions bifurcation, defined as something that demands work on oneself and leads to a narrative reconstruction of one's life. It's about breaking away from the habitual and the usual, and obliging the subject to work on the intersection between the social and biographical levels in order to find new ends or goals, a new coherent form and unity of identity, and thus join a shared world. However, it seems important to acknowledge the interaction between individual choice and constraining so- 
cial structures and parameters (Nilsson \& Nyström, 2013: p. 172). In an influential policy discussion, the Centre for Educational Research and Innovation of the Organization for Economic Co-operation and Development (OECD) discussed a "new" arrangement of the life course: moving from a sequences of stages (full-time education into work into retirement) to what it called "alternation" between periods of work, learning and leisure through the life course (OECD, 1973).

Knowledge about how the individual interprets the world cannot by itself give a deeper understanding of transitions. Only when we include structural factors and analyze the interaction between them and the individual conceptual apparatus does an interpretation become possible. Transitions, in the broadest interpretation, can be understood in terms of societal processes and structure, institutional processes and structure and individual consciousness and activity. In accordance with Giddens (1994), there is a dualism between structure and agent, and it is important to also focus on processes through which a human being, as an active agent, governs his/her relationship with adult education.

The focus of this paper is to present research findings related to certain transitions that have triggered recruitment and participation in learning for some adults. The research question is: What transitions do adults emphasize as being triggers for participation in learning and are they anticipated or unanticipated or do combinations exits? New knowledge about this will be relevant within the field of educational political governance, within the field of practice and for researchers who develop knowledge about adult learning using a lifelong perspective (Table 1).

\section{A Phenomenological Research Approach}

Phenomenology refers to an interest in understanding social events from the individuals' own perspective (Kvale \& Birkmann, 2009). Phenomenology in this study involves an attempt to gain deeper meaning in individual experiences. By looking more closely into adults that experience circumstances surrounding their recruitment to various learning activities, it is possible to consider how transitions can represent triggers for adult learning.

\section{Data Collection}

The findings are based on qualitative interviews among 25 adults participating in different adult education courses. This is a strategic sample, based on an intended variation of different courses, gender and age that were offered at the time of the data collection period. The courses were different hobby- and leisure-based courses, spare-time courses, general studies, vocational education, and university/college studies. The courses were organized as online courses, hybrid courses and ordinary classroom studies where students met face-to-face (Table 2). 
Table 1. Types of transitions.

\begin{tabular}{cll}
\hline & \multicolumn{1}{c}{ Types of transitions } & \\
\hline \multicolumn{1}{c}{ Anticipated transitions } & Unanticipated transitions & \multicolumn{1}{c}{ Nonevents } \\
\hline & & $\begin{array}{l}\text { Expected life events that do not occur. } \\
\text { Personal nonevents are individual aspirations } \\
\text { that do not occur. } \\
\text { Ripple nonevents are unfulfilled expectations of } \\
\text { Expected transitions-life events expected and } \\
\text { predictable as a part of adults life }\end{array}$ \\
& $\begin{array}{l}\text { Unexpected transitions- } \\
\text { unpredictable and stressful life events }\end{array}$ & $\begin{array}{l}\text { Remeone close to us that affects out life. } \\
\text { Result nonevents are a result of another event. } \\
\text { Delayed nonevents are events that still can } \\
\text { happen after the expected time. } \\
\text { Sleeper transitions are nonevents that occur } \\
\text { gradually. }\end{array}$ \\
\hline
\end{tabular}

Table 2. Different courses.

\begin{tabular}{cccc}
\hline & \multicolumn{3}{c}{ Courses } \\
\hline Hobby- and leisure courses & General studies & Vocational education & University studies \\
\hline & & Healthcare & Psychology \\
Copy Boat-driver course & University qualification studies & Housekeeper & Pedagogy \\
Spanish course & General studies & Business Economics & Organization and management \\
Interior course & & Office courses & IT-studies \\
& & Cleaning course & Law degree \\
\hline
\end{tabular}

Participants were recruited through the course providers, who asked their students if one or two of them would like to participate in the study. Included in the interviews were six males and 19 females. The interviews lasted for one to two hours. All adults participated in voluntary education, and the different education programs were arranged by various adult education organizers; the courses varied from classroom lectures and correspondence courses, to data-based distance education.

Some of the courses were prestigious, in the sense that they had strict requirements in relation to admission and completion. Some courses were structured in such a way that they made great demands in terms of being structured and requiring the student to be able to work independently.

This interview material is part of a larger study that forms the basis for my doctoral work (Tønseth, 2011). First and foremost, the intention with the interviews was to investigate the whole process, from recruitment to finishing the courses. Therefore, the participants were interviewed three times during their participation. Adult learning motives, recruitment and choice of courses, organization of everyday life where learning activities are included, support and counselling, financing, mastering and outcomes of adult education were the central themes. Associated with these themes, I also tried to identify and describe life situations and the reasons for picking the actual time for participation. These interviews were conducted from autumn 2000 to spring 2002. The researcher conducted the interviews in the office, as well as transcribed the interviews word-for-word (Table 3). 
Table 3. Selection of participants. Organiser, course, age, family, previous education and occupation. $\mathrm{N}=25$.

\begin{tabular}{|c|c|c|c|c|c|c|}
\hline \multirow{2}{*}{ Participants } & \multicolumn{6}{|c|}{ Table Column Head } \\
\hline & School/organiser & Course & Age & Family & Earlier education & Work \\
\hline Marit B & Online School & Psychology & 42 & No family or children & Low Education & Project manager \\
\hline Hilde & Online School & Pedagogy & 36 & Family with one child & Medium Education & Not working \\
\hline Christopher & Online School & $\begin{array}{c}\text { Management and } \\
\text { organisation }\end{array}$ & 28 & Partner. No children & High Education & Team leader \\
\hline Solfrid & Online School & Health and Care & 45 & Single parent. One child & Low Education & Health and care \\
\hline Kenneth & Online School & IT-study & 32 & Family with two children & High Education & IT consultant \\
\hline Sigrid & Online School & $\begin{array}{l}\text { Management and } \\
\text { organisation }\end{array}$ & 27 & No family or children & Medium Education & Audiologist \\
\hline Laila & Online School & Psychology & 49 & $\begin{array}{l}\text { Family with three } \\
\text { children }\end{array}$ & High Education & Teacher \\
\hline Rune & $\begin{array}{l}\text { Correspondence } \\
\text { courses }\end{array}$ & Supervisor school & 40 & Divorced. Three children & Low Education & Railway worker \\
\hline Mia & Online School & Psychology & 35 & Family with four children & High Education & Not working \\
\hline Kjellfrid & Online School & $\begin{array}{c}\text { Management and } \\
\text { organisation }\end{array}$ & 38 & $\begin{array}{l}\text { Divorced (new partner) } \\
\text { two children }\end{array}$ & Medium Education & Petrol station \\
\hline Kathrine & Online School & Secondary school & 30 & Family with one child & Medium Education & Post-official \\
\hline Ellen & $\begin{array}{l}\text { Correspondence } \\
\text { courses }\end{array}$ & Pedagogy & 24 & No family or children & High Education & Teacher \\
\hline Nils & $\begin{array}{l}\text { Correspondence } \\
\text { courses }\end{array}$ & Janitor school & 50 & No family or children & Low Education & Janitor \\
\hline Ann & Online School & $\begin{array}{l}\text { Business and } \\
\text { economics }\end{array}$ & 29 & Family with two children & Medium Education & $\begin{array}{l}\text { Economy } \\
\text { secretary }\end{array}$ \\
\hline Marit & $\begin{array}{l}\text { High school for } \\
\text { adults }\end{array}$ & Health and care & 45 & Family with two children & Low Education & Not working \\
\hline Tor & Education association & $\begin{array}{l}\text { Boatmanship } \\
\text { license }\end{array}$ & 48 & $\begin{array}{l}\text { Family with two foster } \\
\text { children }\end{array}$ & Medium Education & Electrician \\
\hline Solveig & Education association & Supervisor school & 45 & $\begin{array}{c}\text { Divorced (new partner). } \\
\text { Two children. }\end{array}$ & Medium Education & $\begin{array}{l}\text { Team leader } \\
\text { agent }\end{array}$ \\
\hline Hege & $\begin{array}{l}\text { High school for } \\
\text { adults }\end{array}$ & Secondary school & 31 & Family with two children & Low Education & Not working \\
\hline Kjersti & Private high school & Secondary school & 30 & Family with one child & Low Education & Not working \\
\hline Hanne & Education association & $\begin{array}{l}\text { Secretarial and } \\
\text { office }\end{array}$ & 39 & Family with two children & Low Education & Secretary \\
\hline Eilif & Education association & Spanish course & 35 & Partner. No children & High Education & IT consultant \\
\hline Berit & Education association & $\begin{array}{l}\text { Administration } \\
\text { and Management }\end{array}$ & 45 & $\begin{array}{l}\text { Divorced (new partner). } \\
\text { Four children }\end{array}$ & Medium Education & Office clerk \\
\hline Siv & Education association & Law & 22 & $\begin{array}{l}\text { Lived with her sister. } \\
\text { No children }\end{array}$ & Medium Education & Farmer \\
\hline Silvie & Education association & $\begin{array}{l}\text { Interior and } \\
\text { design }\end{array}$ & 31 & Divorced. Two children & Medium Education & Seller \\
\hline Karin & Education association & Cleaning & 38 & $\begin{array}{l}\text { Family with three } \\
\text { children. }\end{array}$ & Low Education & Cleaner \\
\hline
\end{tabular}


The qualitative interview material includes 25 participants, which is an acceptable number. Half of the interviews were conducted by telephone, because of the long distance between the researcher and some of the participants. Although it was a challenge to achieve the same confidential conversation on the phone that is achieved face-to-face, the researcher was aware of this in the interviews and spent time creating a foundation for a confidential conversation. Even so, the telephone-interviews was a little shorter-in average about 45 minutes. As in other studies based on voluntary participation, there is a risk that those who join are gifted individuals who like to expose themselves and who are confident in their own abilities to communicate. The interviewees referred via the organisers could also be ones who organisers believed could give a positive impression of the course by promoting and providing good references. It may also be that those who volunteered felt that they had something special they wanted to communicate-that they had a special story to tell. Such factors, however, are included in the general debate about individuals who agree to participate in surveys.

Among the interviewees, there were more women interviewed than men. The average age among the participants was 37 years, and they are a heterogeneous group with those experiencing different life situations. Some of them have children for which they must prioritise time, while others have no family obligations. Some are married or have partners, while others are single. Some are employed full-time while others have education and learning as their main occupation. Low education corresponds to the primary/elementary level, middle education is equivalent to education at the secondary school level, and high education refers to college/university education. Several of the participants were highly educated prior to taking these classes. The "information power" of the sample, equivalent to the concept of saturation, is about the researcher's consideration of 1) the research question, 2) the specificity of the sample, 3) the theoretical framework in the study, 4) the dialogue quality in interviews and 5) the analysis strategy (Malterud et al., 2015). All in all, the information power of the sample in this study is considered to be relatively high.

Although the motives for participation often were work-related, the participation in learning was a direct result of special life situations where participation in learning was seen as a solution or a means to change or solve a problem or dilemma in life. Creating a new life or new orientation in life was a fundamental goal for nearly all adults.

\section{Analysis}

The process of coding involved three levels of analyses: 1) open coding, 2) axial coding, and 3) selective coding combined with the constant comparative method (Corbin \& Strauss, 1990). During this first phase of the coding process, the data was compared and different categories were identified. The next step was an axial coding where data was pieced together, allowing connections between catego- 
ries. By asking questions and making comparisons, the inductive and deductive thinking process of relating subcategories was the main emphasis at this stage (Corbin \& Strauss, 1990). In the final stage of coding, a selective coding organizes and integrates the categories and themes in a way that articulated a coherent understanding of the phenomenon of study. To strengthening the coding process, the constant comparative method was used to compare the categories with previous studies.

\section{Findings}

The immediate answer to the question about reasons for participation was mostly related to something they wanted to accomplish related to work: a new job, advancement in the current job or increased salary. In addition to these reasons, there often were special situations or occasions in their lives that required and actualized the need for education and learning. All of the participants reported one or several specific events, changes or situations that actualized participation.

One important reason was the actual life situation involving children who had grown more independent. This brought more time that the participants could fill with new activities (Solveig, Tor, Kjellfrid, Berit, Solfrid, Rune, Laila, and Sigrid). Divorce and breakups were also reported as a direct cause (Solveig, Silvie, Berit, Rune, and Kjellfrid), in addition to reorganization and downsizing in the workplace (Rune, Marit, Kathrine, and Nils) that made learning relevant. The triggers that other participants noted included receiving some sort of financial support that they had not previously had (Hege, Christopher, Eilif, Hanne, Karin, Kenneth, and Marit B) or having friends (Marit and Kjersti), relatives (Siv) or coworkers (Ellen, Hilde, Ann, and Kathrine) taking the same course and who inspired and influenced them. Retraining due to illness/rehabilitation (Kjersti, Mia and Nils) was also mentioned as another causative factor. Such triggers seemed to be what was needed to start an education program or course that had been desired for either a long or short time. Although there were more women than men in the sample, the women commonly reported changes in the private sphere as being triggers, while men reported events or changes related to work as triggers. Several informants discussed aggregated transitions or several concurrent events that reinforced each other and actualized learning.

\subsection{New Priorities}

Time that remains after giving priority to the husband or partners' career and after one's own children have become more independent, seems to be a the triggering factor that actualises participation in learning activities and is most connected to life stage and age. Children getting more independent is, in some way, a predictable change in an adult's life, though letting one's own education be put aside in favour of the partners' career development may not always be a predictable cause. Hanne says: 
To be thirty years old means that one feels more self-confident. I also feel that I am much more knowledge than before. Connected to this... the past eight years, I have been taking care of my kids and my home-nothing else. When my husband had received the education and profession he wanted, I thought .... now it is my turn in life. I thought that I had the opportunity to do something about my life. Hege says:

My husband, for example, he thinks it's okay for me to take this course and supports me. I have supported him through his education and work - so it's payback time. The kids thought it was a little odd that I should not be at home when they got home as usual, but they learned fast to take care of themselves and to participate in some housework.

Hege refers to the expectations from her children and her own conscience that dictate her thought that she really should have been more at home and done her "duties" there as usual. The legitimacy of allowing for more time for study and putting greater demands on the children in the family when mom not always present, is compensated for by the fact that she gets full support from her husband. The choice to participate in learning involves both Hege herself and her family, who have to change their daily routines. The family gets a little less time together, and some of the practical duties and tasks in their household have to be distributed in a different way than before. She sees this as a positive opportunity to change the distribution of housework and to involve the children in a different way than before. The same release of time in their families is also true for many of the women I interviewed, such as Solveig, Tor, Kjellfrid, Berit, Solfrid, Rune, Laila and Sigrid.

\subsection{Divorce-A New Starting Point}

The reason that Solveig joined the Supervisor course was that her husband had moved out. She found out that she had to do something with her life, both in terms of giving her life a new meaning and direction, and in demonstrating to herself and others that she actually can manage to stand on her own.

Transitions, to her, were represented by change from being financially dependent on her partner to being self-financing, from being a two-parent family to a single parent family, and from having a partner to being a single person. To increase confidence in herself and to make new contacts and friends in a new environment, the course has become a kind of guiding factor. Solveig says:

I found that I needed a little more education because I really began to work at an early age, while my husband was finishing his education. So when he moved out last year, I found out that now I have to do something for myself too. Then I got hold of the course catalogue and began to look there.

With help from friends and a psychologist after ending the relationship with her boyfriend, she found that more education would be a way to start over and create a more independent life. It was her turn to bet on herself in order to create the basis for a "new" life, with emphasis on security, recognition and autonomy. 
Divorce was also the direct cause for Silvie beginning her course. She needed some time to think about her life and she came to the conclusion that she wanted to create a new direction in life. For her, the interior design school has been a dream for a long time. She has always been interested in colours, décor and design. Silvie is very clear about her goal by attending the course, and at the end, she wants to start her own business. She likes to decide and have influence, and she wants to experience some freedom and flexibility at work. Silvie wants to combine vocational training in cleaning and interior design, and offer her services as a consultant in different construction projects, where the combination of interior constructions and effective cleaning is something she believes is a neglected area. Silvie says:

It was always a dream I had really. I found that I would reboot after the divorce and create a new life for me and my children. [...] I have always been very interested in colours, design, interior, and renovation. So I imagined a new opportunity to get a new job and a fresh start somehow.

She feels that life has taken a new direction that she will exploit and use to her advantage. She will create a separate platform and a "new life".

\subsection{Health Difficulties-Adjustments to a New Life Direction and New Possibilities}

Mia has been fully employed ever since she completed basic training 19 years ago. Because of health problems, she could not continue her job and she was on a prolonged sick leave. A new profession where she could work and experience success in spite of health difficulties was needed. She wants to become a consultant and conduct training in organisational culture and organisational psychology. Mia says: "So the health problems really gave me a push in a new direction, and a sudden space where I could think about my life and my opportunities."

Kjersti had worked as a florist for several years when her back gave her health problems and caused periods of long-term sick leave. Using counsellors at the employment services, she received the opportunity to retrain and considered changing professions. She decided that she would try a more sedentary office job where her back strain would become less painful. Kjersti says: "I hope that this opportunity for new education can help ensure that I stay healthy and that I can contribute and stay in working life much longer."

\subsection{Unexpected Funding Opportunities Acknowledgements}

Solveig had been promised reimbursement for the course costs from her employer. She justifies the employer's payment with attaining the relevant skills that are related to the job and gives credit to her employer. She says:

I have spent much money already on this course. I expect that my employer will reimburse the costs after application (...). Both the colleagues and the boss supports me in several ways. I get the acceptance and the time to study, but there is no on standing cheering. 
In addition to financial support, Solveig perceives motivational support from the work environment and time to study as positive. For her, it gives a kind of legitimacy and understanding in relation to give priority to the studies. She expects to be reimbursed for the skills for which the employer would benefit, which is her triggering factor and motivation. In addition Christopher's employer has agreed to fund the course costs. Christopher says:

The employer covers the expenses and by that, he motivated me to take this course (...) I have my own computer at home, but sometimes I can also use the computer at work (...) not during working hours, but in the evenings. I see those as very positive, supportive and facilitating factors.

Christopher's agreement with the employer means that he can use the computer equipment at work but not use working time to study. He attends a course that is expected to provide an expertise that will directly benefit the employer, and thereby he experiences acceptance and support from employers and colleagues. At the same time, he also experiences pressure and expectations (to complete the course with good results), responsibilities (to not take the course too fast and not use working hours) and the promise of a reward (such as reimbursement, a new position and/or higher wages). The employer may, at times, have a less committed worker, who may also want to be allotted more absences and is more in need of relief at work. The statements show that there are certain expectations that employers should get something in return by investing in employee training and acting in a supportive way. Other participants that also pointed out that they received some sort of financial support included Hege, Eilif, Hanne, Karin, Kenneth and Marit B.

\section{Discussion}

By interviewing adults who participated in different educational courses, it was discovered that there often were special circumstances or changes that made adults take the final step towards participation in different learning activities. Free time and time left over for study, as well as divorce and breakups, reorganisation at work, dismissal, illness and financing opportunities, were triggering factors that, in some way, demanded a new orientation in life that actualised education and learning. In one way, such triggers forced adults to participate in learning even if they were not motivated. However, for some adults, it was what was needed to embark on an education programme or a course that they had desired for a long time. These events can be defined as transitions that allow for fundamental changes in the adult's life.

The transitions mentioned by the participants were caused by both individual and structural changes. This dichotomy is mentioned in Knowles' book. The modern practice of adult education, from pedagogy to andragogy (1988), where the focus is on individualistic theory with an emphasis on intrinsic motivation and autonomous adults, and the individual needs orientation is the basis for adult learning. In contrast, the focus is directed towards a more radical and 
Marxist-inspired tradition, where the triggers are related to empowerment and structural triggers that contribute social change, as Giddens (1991) and Beck (1992) pointed out.

Knowles (1988) claimed that adults become ready to learn when their life situation creates a "need to know". But, as the findings indicate and as Giddens (1991) points out, age will increasingly be less suited for determining the stage of life. It is the individual and his or her situation or life cycle that more commonly determines the individual's needs and wants.

Mezirow (1991) and his transformational theory also attempt to integrate both the individual and collective/structural orientation. This theory applies primarily to individual learning, which indirectly may have collective change goals (Mezirow, 1991). In the current research's interpretation, various theoretical perspectives linked to the goals of lifelong learning-1) personal fulfillment and development throughout life, 2) active citizenship and social inclusion and 3) employment, wealth creation and social change-are found. The events mentioned in this study are certainly connected to these goals; for instance, a divorce can drive a person towards a new direction in life where they want to develop themselves as persons through learning and education.

In a continuous interaction between individual needs and interests and the environments' requirements and expectations, adults seem to be in a state of continuous readiness for acquiring new knowledge. There are transitions and events in life that cause them to ask questions about the world and themselves, and this questioning is fundamental to adult learning (Jarvis et al., 1998; Mezirow, 1991). These events are not necessary linked to a specific life-phase, but rather, are more about reorientation and a reassessment and restructuring throughout life (cf. Edwards, 1997). This suggests that perhaps we, as researchers, should do some rethinking about adult learning, acknowledging the possibility that adults enter the so-called autonomous stage much earlier than before, while they are young pupils at school and young students at the university. Early in life, we learn about our opportunities and requirements in relation to reflexivity (Beck, 1992; Giddens, 1991).

Transitions that the participants mentioned were both anticipated and unanticipated. One important reason was the actual life situation of having children who had become independent adults, which released more time for learning. These transitions were highly anticipated and predictable. Divorce and breakups, reorganisation and downsizing in the workplace, unexpected financial support, friends, relatives or coworkers taking the same course and who inspired and influenced them, and retraining due to illness/rehabilitation were all factors that were relatively unanticipated. In addition, there were also nonevent transitions and "sleeper" transitions (Schlossberg, 1989). These included the gradual deterioration of a relationship that culminated in a divorce or participating in earlier courses that had made the participants increasingly competent, independent, or self-assured. 
The findings show that triggers are often related to transitions in an adult's life. A divorce means the transition from married to single life and from a two-parent to a single parent household. Other transitions include from employed to unemployed, from one job to another, and from being healthy to sick. This shows that some of the triggering factors may, in some way, be age- and phase-related, while others can be unpredictable and not really related and are limited to certain age and life phases. These transitions all means changes, with certain risks and uncertainties, as Beck (1992) emphasises.

One of the most central theories about adult motives for learning focuses on life crises, or particular happenings in adults' lives that make adults re-value their own lives and life situations in order to find new solutions or new direction in life. Life situations that create a need to know are also something that Knowles and colleagues (1998) and Havinghurst (1972) emphasised. This perspective is something that Mezirow (1991) discussed in his transformative learning theory. However Mezirow focused on the learning process and not on recruitment to learning activities. Changes in life situations follow what Mezirow (1991) termed as a disorienting dilemma, which seems to be a catalyst in transformative learning processes. The causal conditions that lead to transformative learning begin with a disorienting dilemma, such as a life event, an adult education experience, or a new or revised life role (Kroth \& Boverie, 2000).

Participants also experienced several events that acted together and reinforced each other. The fact that their children became more independent while the adults were experiencing a divorce, were examples of such diverse events that include a combination of both expected and unexpected events. A growing dissatisfaction with their own lives along with an unexpected gift of money was another combination that participants mentioned. Termination of one's job coinciding with an interesting course offering emerged as another concurrent event mentioned.

Personal nonevents are defined as the aspirations a person has about his or her life that do not materialise, like being promoted or getting married. Such nonevents mentioned by the participants were expectations concerning their career that were not met because of illness or layoffs at work. Based on the definitions of different transitions, this is an example of an aggregate transition, which is about expectations that meet different obstacles.

As an answer to the initially described research question in this paper, the transitions that the participants emphasised were caused by both individual and structural changes in their lives, related to both to the private and intimate sphere, as much as to the open and public work-related sphere. Transitions were both anticipated and unanticipated, and often occurred in combination. Participants also experienced several events that acted together, aggregating and reinforcing each other.

Good relations, health and employment are important for our identity. Fundamental changes in life mean identity disorders that one would strive to en- 
hance or reinforce in order to create safety and security (Beck, 1992). Such changes mean reorientation in life. Today, divorce and partner change are not unique and happen all of the time. Thus, we all need to be more adaptable and willing to change. At the same time, we can more freely shape our identity regardless of class, which previously created an obstacle and could not be changed (Giddens, 1991). The new modernity poses new challenges, but also greater manoeuvrability.

While we can understand transitions as both personal and public issues, Field (2013) points out that contemporary conditions have tended to individualise them and emphasise the individual's responsibility for their own life planning. The "silent explosion" of adult learning (Field, 2006) that has been experienced in many western countries includes much that might be described as "transitional learning" (Glastra et al., 2004: p. 292). Adults now face a crowded world of learning activities designed to help them through transitions. Field (2013: p. 35) argues that learning itself is not only a passive factor, it also has become an active enabler of change, allowing people to anticipate events and actively plan their future lives.

This "silent explosion" has implications for adult learning policies, practice and research. Those who support adult learners must develop the resources and capabilities to support their learner's requirement to adapt and to anticipate change creatively. Policies for lifelong learning have themselves promoted the flexibility and intensification of transition processes, so they have themselves contributed to the destandardization and restructuring of the adult life course (Field, 2013: p. 4). Still, we need more research on this topic. When it comes to adult life, research on transitions is still relatively underdeveloped (Field, 2013: p. $6)$.

\section{Conclusion}

As a conclusion, we can say that it is important to be aware of different events and nonevents in adults' life, so adults can manage their own choices and life-directions the best way. The results in this study are especially useful for career counsellors, whose ambition is to help adults in taking conscious and reflected choices. Career counsellors that are aware of the different "triggers" will probably more easily be able to choose the right guidance strategy.

\section{References}

Aslanian, C. B., \& Brickell, H. M. (1980). Americans in Transition: Life Changes as Reasons for Adult Learning. New York: College Entrance Examination Board.

Bauman, Z. (2005). Liquid Life. Cambridge: Polity.

Beck, U. (1992). Risk Society: Towards a New Modernity. London: Sage.

Biesta, G. J. J., Field, J., Hodkinson, P., Macleod, F. J., \& Goodson, I. F. (2011). Improving Learning through the Life Course. Learning Lives. London: Routledge.

Brown, P. (2003). The Opportunity Trap: Education and Employment in a Global Economy. European Educational Research Journal, 2, 142-180. 
https://doi.org/10.2304/eerj.2003.2.1.4

Corbin, J., \& Strauss, A. (1990). Grounded Theory Method: Procedures, Canons, and Evaluative Criteria. Qualitative Sociology, 13, 3-21. https://doi.org/10.1007/BF00988593

Danish, S. J., Smyer, M. A., \& Nowak, C. A. (1980). Developmental Intervention: Enhancing Life-Event Processes. In P. B. Baltes \& O. B. Brim Jr. (Eds.), Life-Span Development and Behavior (pp. 340-366). New York: Academic Press.

Edwards, R. (1997). Changing Places? Flexibility, lifelong Learning and a Learning Society. London: Routledge.

Field, J. (2006). Lifelong Learning and the New Educational Order. Stoke-on-Trent: Trentham Books.

Field, J. (2009). Learning Transitions in the Adult Life Course: Agency, Identity and Social Capital. In B. Merrill (Ed.), Learning to Change? The Role of Identity and Learning Careers in Adult Education. Frankfurt am Main: Peter Lang.

Field, J. (2011). Researching the Benefits of Learning: The Persuasive Power of Longitudinal Studies. London Review of Education, 9, 283-292. https://doi.org/10.1080/14748460.2011.616320

Field, J. (2013). Lifelong Learning and the Restructuring of the Adult Life Course. In W. Schröer, B. Stauber, A. Walher, L. Böhnisch, \& K. Lenz (Eds.), Handbuch Übergänge (pp. 378-393). Beltz Juventa: Weinheum and Basel.

Gallacher, J., Ingram, R., \& Field, J. (2009). Learning Transitions: Research, Policy, Practice. In J. Field, J. Gallacher, \& R. Ingram (Eds.), Researching Transitions in Lifelong Learning (pp. 1-6). London: Routledge.

Giddens, A. (1991). Modernity and Self Identity: Self and Society in the Late Modern Age. Cambridge: Polity Press.

Giddens, A. (1994). Modernitetens konsekvenser. [The Consequences of Modernity]. København: Hans Reitzels Forlag.

Glastra, F. J., Hake, B. J., \& Schedler, P. E. (2004). Lifelong Learning as Transitional Learning. Adult Education Quarterly, 54, 291-307.

https://doi.org/10.1177/0741713604266143

Havinghurst, R. (1972). Developmental Tasks and Education. New York: David McKay.

Jarvis, P., Holford, J., \& Griffin, C. (1998). The Theory and Practice of Learning. London: Kogan Page.

Knowles, M. S., \& Elwood, F. (1998). The Adult Learner: The Definitive Classic in Adult Education and Human Resource Development. Houston, TX: Gulf Publications Company.

Knowles, M. S. (1988). The Modern Practice of Adult Education: From Pedagogy to Andragogy. Englwood Cliffs, NJ: Cambridge Adult Education.

Kroth, M., \& Boverie, P. (2000). Life Mission and Adult Learning. Adult Education Quarterly, 10, 134-149. https://doi.org/10.1177/07417130022086955

Kvale, S., \& Birkman, S. (2009). Interviews: Learning the Craft of Qualitative Research Interviewing (2nd ed.). Los Angeles: Sage.

Levinson, D. J. (1978). Seasons of a Man's Life. New York: Random House.

Malterud, K., Siersma, V. D., \& Guassora, A. D. (2015). Sample Size in Qualitative Interview Studies: Guided by Information Power. Qualitative Health Research, 26, 1753-1760. https://doi.org/10.1177/1049732315617444

Merriam, S. B. (2005). How Adult Life Transitions Foster Learning and Development. 
New Directions for Adult and Continuing Education, 108, 3-13.

https://doi.org/10.1002/ace.193

Mezirow, J. (1991). Transformative Dimensions of Adult Learning. San Fransisco: Jossey-Bass.

Neugarten, B. (1976). Adaptation and the Life Cycle. Counseling Psychologist, 6, 16-20. https://doi.org/10.1177/001100007600600104

Nilsson, S., \& Nyström, S. (2013). Adult Learning, Education, and the Labor Market in the Employability Regime. European Journal for Research on the Education and Learning of Adults, 4, 171-187. https://doi.org/10.3384/rela.2000-7426.rela9007

OECD (1973). Recurrent Education-A Strategy for Lifelong Learning. Brussels: OECD Publishing.

Pita Castro, J. C. (2014). The Transition from Initial Vocational Training to the World of Work: The Case of Art School Students. European Journal for Research on the Education and Learning of Adults, 5, 111-126.

https://doi.org/10.3384/rela.2000-7426.rela0107

Salling Olesen, H. (2000). Experience and Life History. Roskilde University Life History Project. Paper No-9. Roskilde: Roskilde University Center.

Schlossberg, N. K. (1989). Overwhelmed: Coping with Life's Ups and Downs. Lanham, MD: Lexington Books.

Schlossberg, N. K., Waters, E. B., \& Goodman, J. (1995). Counseling Adults in Transition (2nd ed.). New York: Springer.

Thiessen, V., \& Looker, E. D. (1999). Diverse Directions: Young Adults' Multiple Transitions. In W. R. Heinz (Ed.), From Education to Work: Cross-National Perspectives. Cambridge: Cambridge University Press.

https://doi.org/10.1017/CBO9780511527876.004

Tønseth, C. (2011). Voksne i læring. Identitetskonstruksjon i lys av Kompetansereformen. [Adults Participating in Learning Activities. Identity-Construction in the Light of the Norwegian Competence Reform.] PhD Dissertation, Trondheim: Department of Sociology and Political Science, Norwegian University of Science and Technology (NTNU). 